\title{
BOOK REVIEW
}

Klaus D. Schmidt (2002): Versicherungsmathematik. Springer, Berlin. viii + 320 pages, ISBN 3-540-42731-7.

The book "Versicherungsmathematik" by Klaus D. Schmidt is an introductory textbook covering selected topics of life insurance mathematics and mathematical risk theory. It addresses undergraduate students of mathematics and economics, attempting to provide them with some insight into the vast field of actuarial mathematics.

CONTENTS:

Einleitung

1. Finanzmathematik

2. Wahrscheinlichkeiten

3. Zufallsvariable und ihre Verteilungen

4. Momente von Zufallsvariablen

5. Lebensversicherung

6. Gesamtschaden im individuellen Modell

7. Gesamtschaden im kollektiven Modell

8. Rückversicherung

9. Vergleich von Risiken

10. Kalkulation von Prämien

11. Reservierung für Spätschäden

Sterbetafeln

Literatur

Verzeichnis der Symbole

Verzeichnis der Beispiele

Namenverzeichnis

Sachverzeichnis

The necessary prerequisites are some basic knowledge of analysis, of algebra and of probability. As can already be seen from the table of contents above, a brief introduction to elementary (deterministic) financial mathematics and to elementary probability is part of the book. In this sense, the book is more or less self-contained. In accordance with the scientific focus of the author, the chapters on risk theory are particularly well-written. This applies especially to the chapters on reinsurance, premium calculation and claims reserving. They demonstrate that even in a rather elementary book like this, model-based treatments of actuarial techniques used in practice can be included. It is one of the distinguished features of this textbook, that it is - for nonexperts as well as for experts - fairly easy to pick out and read any single chapter of interest and to provide oneself with the prerequites from other chapters while proceeding. This book will be useful to students and teachers of actuarial mathematics, and it will also provide practitioners with additional insight.

Hartmut Milbrodt 